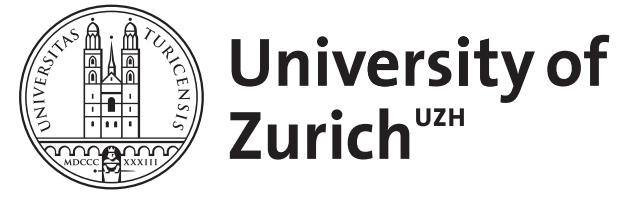

\title{
Dual character concepts
}

\author{
Reuter, Kevin
}

DOI: https://doi.org/10.1111/phc3.12557

Posted at the Zurich Open Repository and Archive, University of Zurich ZORA URL: https://doi.org/10.5167/uzh-174293

Journal Article

Published Version

Originally published at:

Reuter, Kevin (2019). Dual character concepts. Philosophy Compass, 14(1):e12557.

DOI: https://doi.org/10.1111/phc3.12557 


\section{Dual character concepts}

\section{Kevin Reuter (10}

University of Bern

\section{Correspondence}

Kevin Reuter, Institute of Philosophy, University of Bern, Unitobler Länggassstraße 49a, 3012 Bern, Switzerland.

Email: kevin.reuter@philo.unibe.ch

Funding information

Schweizerischer Nationalfonds zur Förderung der Wissenschaftlichen Forschung,

Grant/Award Number: 100012_169484

\begin{abstract}
Some of philosophy's most central concepts, including art, friendship, and happiness, have been argued to be dual character concepts. Their main characteristic is that they encode not only a descriptive dimension but also an independent normative dimension for categorization. This article introduces the class of dual character concepts and discusses various accounts of their content and structure. A specific focus will be placed on their relation to two other classes of concepts, thick concepts and natural kind concepts. The study of dual character concepts not only demonstrates that a wide range of concepts is inherently normative, but it also reveals new possibilities for investigating gender biases, generics, and social roles.
\end{abstract}

\section{1 | WHAT ARE DUAL CHARACTER CONCEPTS?}

Most of our concepts seem to be either purely descriptive, e.g., meadow and playing tennis, or purely normative, e.g., fantastic and abysmal. The class of thick concepts has long been thought to provide the only exception. ${ }^{1}$ Thick concepts, such as generous and rude, are substantially descriptive but also involve evaluation. ${ }^{2}$ Within the past few years, researchers have begun to investigate a new class of part descriptive, part normative concepts, the so-called dual character concepts (Del Pinal \& Reuter, 2017; Knobe, Prasada, \& Newman, 2013; Leslie, 2015). Dual character concepts are unique in that their descriptive and normative dimensions are related but independent. To illustrate their properties, take the example of the concept artist. On the one hand, we consider a person to be an artist if certain descriptive aspects, such as painting pictures for a living, are met. On the other hand, we may also conceive of a person as an artist if she satisfies norms that spell out what we believe an artist should be or should do, for instance, be committed to creating works of deep esthetic value. Consequently, people can categorize a person as an artist, if she fulfills the descriptive, or the normative criterion, or both. Note that the normative dimension of artist is not a matter of being particularly good at being an artist: The set of good artists forms a proper subset of the set of all artists. In contrast, many people who are committed to creating works of deep esthetic value do not belong to the set of artists that satisfy its descriptive features. 


\subsection{Which concepts are dual character?}

One might initially think that dual character concepts are restricted to social role concepts such as artist, father, or criminal, and artifact concepts like painting and jazz, which have an undeniable link to the social domain. ${ }^{3}$ After all, the most extensive studies of dual character concepts so far have focused on artifact and social role concepts (Knobe et al., 2013) or social role concepts only (Leslie, 2015; Del Pinal \& Reuter, 2015, 2017, ms). Other studies, however, suggest that some of philosophy's most fundamental concepts may also have a dual character structure: Phillips, De Freitas, Mott, Gruber, and Knobe (2017) argue that the ordinary concept of happiness has an independent normative dimension by including a place for moral value (see also Chituc, 2012). Liao, Meskin, and Knobe (n.d.) argue that the concept art is a dual character concept and thereby provide a new solution to the debate of whether "art" is a descriptive or evaluative term. Buckwalter, Rose, and Turri (2015) distinguish between thin and thick beliefs, where a thin belief that $p$ merely involves storing $\mathrm{p}$ as information. A thick belief that $p$, however, requires a person to emotionally endorse $p$. Although Buckwalter et al. do not argue for belief to be dual character, developing a two-fold structure for belief makes room for such an interpretation. ${ }^{4}$ Work by Newman, De Freitas, and Knobe (2015) suggests that the notion of self allows for two different dimensions: one descriptive and one that is normatively laden. Thus, the study of dual character concepts not only is an intriguing research subject in itself but also has wide-ranging consequences for a host of philosophical and psychological topics.

\section{2 | Methods, operationalization, and empirical investigation}

From its very beginning, the study of dual character concepts has been empirically grounded, no doubt in large part due to Knobe et al.'s (2013) work. In their seminal paper on dual character concepts, Knobe et al. propose two different ways to operationalize the notion of a dual character concept. First, the "two-senses" approach (see also Machery \& Seppälä, 2011) asks us to consider the following two pairs of sentences:

(1a) There is a sense in which she is a scientist [optician]/it is jazz [a table].

(1b) However, when you think about what it really means to be a scientist [optician, jazz, table], you would have to say that she is not a scientist [optician]/it is not jazz [a table] after all.

(2a) There is a sense in which she is not a scientist [optician]/it is not jazz [a table].

(2b) However, when you think about what it really means to be a scientist [optician, jazz, table], you would have to say that she is a scientist [optician]/it is jazz [a table] after all.

Most people accept all four statements for scientist and jazz but reject the (b)-statements for optician and table, revealing that scientist and jazz but not optician and table encode an independent normative dimension for categorization. ${ }^{5}$ Aristotle (350 BCE) was perhaps the first philosopher to highlight the dual nature of some concepts when discussing what it means to be a friend and provided us with a second method of operationalization. Aristotle famously wrote that we think of people as friends if they are useful or are pleasurable company, although "it is those who desire the good of the friends for the friends' sake that are most truly [emphasis added] friends" (p. 263). This passage not only suggests friend to have two independent criteria for its application, but it also exemplifies that the "true" modifier singles out its normative dimension. Thus, when stating "Federer's second serve is a true piece of art," we seem to pick out the normative dimension of the concept art. Empirical studies (Knobe et al., 2013) have supported the idea that the normative dimension of dual character concepts can be picked out by expressions such as true friend or true artist, and that its properties can be investigated by examining the acceptability patterns of those expressions under various manipulations of contextual information (Del Pinal \& Reuter, 2017). Providing such contextual information can add an ad hoc normative dimension to concepts that would usually not be judged dual character. Consider, for instance, a school bus driver who drives recklessly in heavy traffic. Given this background information, 
you might think that a true bus driver makes sure children arrive home safely (see also Leslie, 2015, for a more elaborate discussion of this example).

Many of the subsequent studies on dual character concepts (Del Pinal \& Reuter, 2015, 2017, ms; Liao et al., n.d.; Newman, Bloom, \& Knobe, 2014; Phillips et al., 2017; Tobia, Newman, \& Knobe, ms) apply at least one of these two methods and aim to support their theoretical claims with empirical data. Even though the application of these methods has certainly delivered fascinating results, their use is not without challenges. First, the two-senses method is arguably too vague concerning the meaning of the term "sense," which can be interpreted in a wide variety of ways. Second, the "true-modifier" approach suffers from the fact that the term "true" has many different meanings and uses: (a) There is, of course, the standard philosophical sense according to which a proposition like "Snow is white" is true or false; (b) "true" is often used as a hedge (Lakoff, 1975) as in "A sparrow is a true bird," where the true-modifier highlights that a sparrow not only satisfies the defining features of a bird but also has most prototypical features of birds. In contrast, a penguin does not look like a typical bird, and hence, many people consider penguins to be merely technically speaking birds; (c) "true" is also used as an intensifier to raise the standard of application as in, "This is a true cookie." Using the true-modifier in one of these three alternative meanings does not show that we are dealing with dual character concepts: Neither proposition, nor sparrow, nor cookie has an independent normative dimension for categorization. Given these worries, it is certainly desirable to develop a more comprehensive toolkit for the investigation of dual character concepts. ${ }^{6}$

\section{I THE NORMATIVITY OF DUAL CHARACTER CONCEPTS}

\subsection{The content of the normative dimension}

One of the major research questions in the literature on dual character concepts is concerned with identifying their normative content. Before we discuss three specific accounts, let me first address the more general question of how we can understand the idea that dual character concepts have a normative dimension for categorization. When we ask ourselves what a father should do, or in which circumstances one should be happy or angry, we consider these questions to be normative. Answers to such should-questions have been argued to lack descriptive import but instead have an action- or reason-guiding role; i.e., they recommend (or even demand) a certain course of action or thought. ${ }^{7}$ Perhaps the most surprising insight about dual character concepts is that for these concepts, an actionor reason-guiding aspect (yet to be specified) takes on a classificatory role. For instance, according to a more traditional picture, a father is a male biological parent and should be committed to look after his offspring: Whether or not a man is indeed committed to look after his offspring is irrelevant for classifying him as a father (because it is merely something a father should do, not what makes him a father). However, dual character concepts seem to work differently. If a male biological parent does not care about his offspring, there seems to be a sense in which that person is not a father. And conversely, if a person looks after a child that is not his biological offspring, then there is a sense in which that person is a father. The same cannot be said for concepts that are not dual character: Whatever one believes a cashier should do, e.g., be committed to processing transactions, care about money, and be polite to customers, there seems to be no sense in which a person ceases to be a cashier if s/he does not satisfy such actionguiding norms. Given these considerations, how should we specify the normative content that takes on a "classificatory life on its own"?

Three accounts have so far been posited. First, Knobe et al. (2013) propose that the normative dimension represents certain abstract values associated with the corresponding descriptive elements. For example, the normative dimension of scientist represents a value, such as the pursuit of empirically informed theories that is realized by its descriptive components such as analyzing data, writing papers, and constructing theories. Second, focusing on social roles mainly, Leslie (2015) proposes a distinction between typical functions of a role (e.g., philosophers teach metaphysics, criticize existing metaphysical theories, and devise new metaphysical accounts) and an idealized social 
function. According to Leslie's view, the normative dimension of social roles represents their primary idealized function; for instance, a true philosopher is concerned with the larger questions. Third, drawing on Leslie's proposal, Del Pinal and Reuter (2017, ms) have argued and provided empirical evidence that the normative dimension of social role concepts represents the commitment to fulfill the idealized function associated with that role. Thus, if an artist is committed to producing works of esthetic value, then she satisfies the normative dimension of the concept artist.

All three accounts create space for substantial individual disagreement concerning the content of the normative dimension of dual character concepts. Both Leslie (2015) and Del Pinal and Reuter (2017) explain these differences by referring to individual disagreements on what the respective idealized functions are. However, there are also important constraints. Leslie predicts that secondary social functions can hardly be drawn upon to create a normative dimension. Consequently, although caseworkers can be said to have the secondary social function of providing some emotional support, this function cannot serve to be encoded as the normative dimension of caseworker. Relatedly, Del Pinal and Reuter show that the commitment that features in their account must be directed to the function as an end in itself, but not as means to another end. Accordingly, even if a person is committed to creating works of esthetic value, that person fails to be a true artist if her commitment is a means to her ultimate aim of earning a lot of money. Both Leslie's proposal and the commitment account by Del Pinal and Reuter make rather specific proposals, but it is uncertain whether these accounts can be extended to artifact kinds, such as poem, sports car, and emotion concepts. In contrast, Knobe et al.'s (2013) abstract value account certainly has the advantage to encompass a wider range of concepts that have been identified to be dual character, but talk of abstract values seems too vague.

Whereas many controversies remain in regard to detailing the normative content of dual character concepts, a further issue arises as to if and how strongly both dimensions interact. To illustrate, imagine that Tom satisfies the descriptive features of being a colleague by working for the same company and in the same field as his co-workers but fails to fulfill the normative requirements of being a colleague by not caring to support his co-workers. Tom is certainly not a true colleague. But is he a colleague? While this question has not so far been systematically investigated, some empirical results suggest that the answer is at least in part negative. For instance, Knobe et al. (2013) were able to show that many people do not regard a person to be an artist if she does not care about esthetic values; and Phillips et al. (2017) demonstrated that many people refuse to attribute happiness to a person who feels satisfied for morally dubious reasons. These results suggest a substantial impact of the normative component on seemingly descriptive classification tasks.

\subsection{Normativity and social cognition}

Empirical studies have shown that the encoding of a normative dimension is particularly salient for social role concepts (Knobe et al., 2013) and gender terms (Leslie, 2015). For instance, expressions like "true philosopher" and "true woman" seem to be highly acceptable and particularly frequent. This discovery has important implications for social cognition because the extent to which people believe other persons to satisfy the normative dimension of certain social roles is likely shaped by aspects such as gender, age, intelligence, and many other socially relevant factors. These influences will in turn guide our thinking not only about social roles themselves but also about the ability of members of certain social groups to fulfill their normative demands. Focusing on the interaction between gender and the normative dimension of social role concepts, a series of papers has started to draw on their dual character to investigate both normative generics and gender biases, which I will discuss in turn.

Generic sentences have been argued to express our primitive generalizations about the world (Leslie, 2008), and some of them seem to express very substantial social biases (Haslanger, 2014; Wodak, Leslie, \& Rhodes, 2015); e.g., "boys don't cry." How can we understand and explain such generics and at the same time agree with statements like "boys cry"? Leslie (2015) argues that the normative dimension of social role concepts may be a key determinant of the meaning of such normative generics. She maintains that the "seemingly contradictory pair of generics is 
consistent because one picks up the normative sense of the term, and the other picks up the descriptive sense of the term" (p. 7). Leslie's discussion of normative generics also allows her to make an interesting proposal of why some of our concepts have a normative dimension. If the normative dimension of dual character concepts indeed encodes idealized social functions, we can easily see why those concepts have such a dimension: It allows the preservation of ideals that are supported by widespread agreement. Generic statements that seem to violate this proposal; e.g., a mother who tells her daughter that "true girls do not cry" can be argued "[to] say something false, but with the intention of changing the widely held ideal concerning girls" (Leslie, 2015, p. 11). ${ }^{8}$ Whether or not Leslie's account can handle other possible counterexamples needs to be seen. In any case, drawing on the dual nature of social role concepts suggests that a more comprehensive theory of social generics can be given.

The investigation of the dual nature of social role concepts is also likely to provide additional tools for studying gender biases. Experiments by Knobe et al. (2013) and Del Pinal and Reuter (2015) have shown that the modifier "true" picks out the normative dimension of social role concepts; e.g., a true soldier is a person who satisfies some abstract value that is associated with being a soldier. The results of these studies reveal that while some social roles concepts have a strong normative dimension by default (artist, mechanic, soldier), other social role concepts (baker, cashier, florist) only weakly represent a normative component. Recent work by Reuter and Del Pinal (n.d.) utilizes the true-modifier approach to investigate whether men and women are considered to equally satisfy the normative aspects of social role concepts. The results of their studies indicate that there is a significant bias against women in many gender-associated social roles. More specifically, on average, people agree more strongly with a claim such as "Jack is a true x" compared to "Mary is a true x," when $\mathrm{x}$ is a gender-associated social role like soldier, mechanic, florist, nurse. In contrast, for gender-neutral social roles like baker, editor, and musician, no difference was observed. The exact nature of this bias is, of course, dependent on what is encoded in the normative dimension of social role concepts. According to the account advanced by Del Pinal and Reuter (2017), the normative dimension of dual character concepts represents the commitment to fulfill the function of the social roles. If their account proves correct, then the observed effect is the result of a specific gender bias such that arbitrary male members are considered more committed to certain social roles than are female members. The results are certainly preliminary, but its results are sufficiently robust to direct attention towards a gender bias that has so far not only been neglected (but see Bielby, 2000; Bielby \& Baron, 1986) but also lacks any empirical foundation. ${ }^{?}$

\section{I DUAL CHARACTER CONCEPTS, THICK CONCEPTS, AND NATURAL KIND CONCEPTS}

Dual character concepts form a class with unique properties. Two other kinds of concepts, however, appear to have properties that are in some important respect similar to those of dual character concepts. While thick concepts resemble dual character concepts in having a normative component, natural kind concepts seem to be structurally similar to dual character concepts in sharing two different criteria for category membership. I discuss various similarities and differences between these classes, starting with thick concepts.

\section{1 | Thick concepts}

Thick concepts not only describe certain states of affairs but also evaluate them positively or negatively. For instance, while the statement "Sarah is willing to take risks" merely describes a certain character trait of Sarah, "Sarah is courageous" additionally evaluates her risk taking positively, whereas "Sarah is foolhardy" evaluates her willingness to take risks negatively. Importantly, the terms "courageous" and "foolhardy" are descriptively richer than "great" or "bad," which merely evaluate but do not specify in which sense something is considered positively or negatively (Väyrynen, 2016). Similar to discussions on dual character concepts, the most prominent debate on thick concepts revolves around the question of how the descriptive and normative components are related. According to the 
standard account, it is not possible to disentangle the descriptive and evaluative components of these concepts (Kirchin, 2010; Putnam, 2002; Williams, 1985), but see Elstein and Hurka (2009) or Väyrynen (2013) who have argued against the anti-disentanglement thesis.

Whereas the normative aspect of thick concepts is usually thought to be evaluative in character, I have argued that the normativity of dual character concepts can be understood through its action- or reason-guiding role. It is, therefore, not entirely clear that both kinds of concepts are normative in the same sense. ${ }^{10}$ It seems that the evaluative component of thick concepts can easily be given an action-guiding interpretation: A woman who is courageous is positively evaluated for her risk taking because we believe that she should be taking these risks (or that her behavior is at least to be recommended), whereas a person who acts foolhardily is negatively evaluated for her risk taking, because we think that she should not be taking those risks. It is less obvious, however, that a person or an object that satisfies the normative dimension of a dual character concept is thereby also always evaluated in a positive or negative way. In fact, it seems highly questionable that expressions such as "true conservative" or "true soldier" must be saying something either good or bad. I believe we can explain this possible lack of evaluative character by highlighting that people can also take a neutral stance towards action-guiding norms themselves. For instance, a person can acknowledge that the action-guiding norm of soldiers is to put country before self but nonetheless take a critical or even neutral stance towards it. Certainly, more work is needed to detail the various aspects for which both thick and dual character concepts can be said to be in part normative.

At least two crucial differences need to be noted between thick concepts and dual character concepts. First, on all accounts, the normative component of thick concepts "merely" evaluates what the descriptive component refers to and, hence, has no independent content in and of itself. Hence, the normative component precludes independent categorization; e.g., it seems impossible to call Sarah courageous without also describing her as a risk-taking individual. Second, and relatedly, expressions of dual character concepts do not allow us to draw any inferences about their evaluative valence. For example, hearing from Sam that Susan is an artist does not provide us with any information on whether Sam looks favorably on Susan or not. The situation is markedly different with thick concepts: When Sam calls Susan "courageous," he expresses a clear pro-attitude, unless additional contextual information is provided (Blackburn, 1992; Hare, 1981).

Despite the fact that research on thick concepts has flourished during the last three decades, no empirical studies seem to have been conducted in this area. This is surprising because "the claim that how people actually use their normative concepts is an empirical question should not be controversial" (Tiberius, 2013, p. 222). Thus, by investigating the relation between thick concepts and dual character concepts empirically, much progress is to be expected. Some of the connections between thick concepts and dual character concepts can be examined by analyzing concepts that are both thick and dual character, e.g., friend and criminal. Studying thick concepts empirically also allows us to examine possible ways in which the normative component of thick concepts and the normative component of dual character concepts interact. This raises a host of interesting research questions: (i) Can we infer the strength of the normative dimension of a dual character concept from the strength of its thickness? (ii) How do both classes of concepts compare in terms of acceptability and independence of the normative component? (iii) How do people compute the normative dimension of concepts given only its descriptive features? ${ }^{11}$

\subsection{Natural kind concepts}

The standard depiction of natural kinds as having both superficial and core properties (Bird \& Tobin, 2018) motivates the idea that natural kind concepts also encode two independent dimensions for categorization. Accordingly, an animal can be categorized as a tiger either if it fulfills some concrete superficial features like striped, carnivore, cat of prey, etc. or if it has the right tiger essence, like having tiger DNA or being born of tiger parents. Famously, Putnam (1975) has ruled out classification of natural kinds based on superficial properties, highlighting their core properties as necessary for the identification of natural kinds. Empirical results by Knobe et al. (2013) support the claim that natural kind terms do not show the characteristic dual character pattern when being empirically investigated. When people 
were asked to imagine some animal that looks like a tiger and seems to hunt like a tiger but is discovered to have puma DNA, they tended to disagree with statement (a) in the "two-senses" task:

a. There is a sense in which that animal is clearly a tiger.

b. However, when you think about what it really means to be a tiger, you would have to say that it is not really a tiger.

In contrast with dual character concepts, for which there exist two ways of categorization, natural kinds seem to be only identified when the item is believed to carry the respective essential property. The answers that Knobe et al. (2013) recorded are consistent with well-established results in the literature on psychological essentialism (Gelman \& Kremer, 1991; Rangel \& Keller, 2011). The clear distinction between dual character concepts and natural kind concepts, however, has been challenged in regard to both the properties of dual character concepts and natural kind terms. In a recent paper, Tobia, Newman, and Knobe (n.d.) tested people's intuitions for both the famous Twin Earth thought experiment (Putnam, 1973) and other variations of that thought experiment. The aim of these studies was to determine whether people share the standard philosophical intuition that natural kinds are defined by their essences, e.g., the Putnamian intuition that a liquid is water only if it consists of $\mathrm{H}_{2} \mathrm{O}$ molecules. Their results put pressure on the widely held intuition that the identity conditions of natural kinds are necessarily constituted by essential properties. Most participants, in fact, thought that there is a sense in which the liquid on Twin Earth is water but also a sense that it is not. Similar results were obtained for other natural kinds, including tigers, salmon, and gold (see also Bloom, 2007; Machery \& Seppälä, 2011). If natural kind concepts indeed show a dual character pattern, then the effect under investigation is perhaps part of a much wider phenomenon. Such a conclusion is further underpinned by results from Del Pinal and Reuter (2015). Their studies empirically investigated the degree to which the normative dimension of dual character concepts is a central criterion, where a dimension or feature is more central, the more other features depend on it (see also Del Pinal, Madva, \& Reuter, 2017). If it is central, it is present in most of our thoughts and judgments concerning the denoted class. Using Sloman, Love, and Ahn's (1998) "surprise paradigm" to measure centrality, e.g., asking participants how surprised they would be if they encountered an artist who does not care about creating inspiring works of art, they were able to show that the normative dimension is not only loosely associated with the concept but rather a central feature of its structure.

These results suggest that dual character concepts might also be seen as a special kind of prototype in which the normative dimension is not only a highly weighted feature but also a central feature. ${ }^{12}$ Accordingly, dual character concepts have a kind of a hybrid make-up since they encode both statistical information and dependency relations between the features of the concept. However, such hybrid models have recently come under attack by theoretical as well as empirical work by Machery and Seppälä (2011) and Machery (2014). They argue that if concepts are indeed hybrids that consist in a prototypical structure but also encode an essential or theory-based core, we should expect people's judgments in simple classification tasks to be coordinated;i.e., deliberations about whether an object or a kind belongs to a certain class should not lead to conflicting verdicts. However, their empirical studies show that many people happily endorse the view that there is a sense in which, e.g., tomatoes are vegetables but also that tomatoes are not vegetables. In other words, it looks as if prototypical and theory-based information leads to uncoordinated verdicts. They conclude that these empirical results favor the heterogeneity hypothesis or concept pluralism (see also Machery, 2005, and Weiskopf, 2009), according to which there are several conceptual structures for the same category. The rather unequivocal data coming from studies on dual character concepts seems to provide further support for concept pluralism. One might, however, challenge the coordination criterion on either theoretical (Vicente \& Martínez-Manrique, 2014) or empirical grounds. On Knobe et al.'s view, for instance, the normative dimension represents abstract values that are realized by the more concrete features of the descriptive dimension. Hence, at least, in some regard, the descriptive and normative information seems to be coordinated.

Both the conflicting evidence researchers have found in regard to whether natural kind concepts show a dual character pattern, as well as the empirical results on the centrality of the normative dimension of established dual 
character concepts, underscore the need for further empirical work. Such work will be crucial in establishing whether a unified account can be developed that encompasses both natural kind concepts and dual character concepts (Newman \& Knobe, forthcoming). Assuming dual character concepts to be essentialist-like concepts has important implications not only for accounts of conceptual change but also for individual acts of categorization. Since the normative dimension is a central feature of dual character concepts, changes to the normative dimension will have substantial effects on its descriptive features. For instance, if we change the normative dimension of colleague from supporting one's co-workers to competing with them, this will eventually affect the rest of the descriptive criteria of colleague. These are fundamentally important implications that need to be tackled in future studies.

\section{4 | CONCLUSION}

The study of dual character concepts is in its infancy: The first full-length paper on this subject appeared only five years ago. Since then, this research area has flourished as can be witnessed by the wealth of new publications on this topic. In this article, I have surveyed some of the current accounts on the content and structure of dual character concepts, as well as their relation to thick concepts and natural kinds concepts. The discovery of an independent normative dimension raises some formidable challenges to the neat distinction between the descriptive and normative realm for many concepts that many have thought to be purely descriptive.

\section{ACKNOWLEDGEMENTS}

This work was supported by the Schweizerischer Nationalfonds zur Förderung der Wissenschaftlichen Forschung Swiss National Science Foundation (Grant 100012_169484). I would like to thank a reviewer for this journal, as well as the section editor for their extremely helpful comments. Thanks also to Guillermo Del Pinal and audiences at conferences in Hamburg, London, and Munich, where parts of the manuscript were presented.

\section{ENDNOTES}

${ }^{1}$ Recently, experimental studies have shown that normative evaluations influence the application of what are usually considered to be purely descriptive concepts. The concepts of cause and intentional action are probably the most widely discussed cases in point; see, e.g., Knobe (2003), Alicke (2008), and Knobe and Fraser (2008).

${ }^{2}$ For example, by calling a woman "generous," we not only describe her as willing to give money or support beyond what is expected, but we also evaluate her positively for being willing to give that amount of support.

${ }^{3}$ Leslie (2015) argues that dual character concepts have their distinct features because they are in some sense social concepts.

${ }^{4}$ For example, we may say that a person truly believes $p$ only if that person acts in accordance with $p$.

${ }^{5}$ Purely thick concepts like prisoner, or kitsch, do not have an independent normative dimension and hence do not pass the "two-senses" test. Some concepts like friend are both thick and dual character.

${ }^{6}$ Examining other modifiers may deliver important insights, including the modifier real (Malt \& Paquet, 2013), as well as modifiers that have been suggested by Leslie (2015) but which have not so far been investigated empirically, e.g., "Linda is twice the scientist that Tom is" and "Sam is more of an artist than Sarah."

7 For discussions on cashing out the normativity of concepts in terms of their action- and reason-guiding role, see Williams (1985) and Wedgwood (forthcoming).

${ }^{8}$ Del Pinal and Reuter (2017) provide an alternative explanation of why social role concepts encode commitments to idealized functions: That information is crucial to predict the future social roles and role-dependent behavior of others. For instance, if you know that a teenage boy is committed to creating esthetically deep work, then you can predict that he will strive to become an artist. Such a prediction is less reliable if you merely know that this teenage boy is skilled at painting pictures and working with watercolors.

9 The potential for studying biases is, of course, not merely restricted to gender biases but can be extended to racial and other biases.

10 I would like to thank a reviewer of this journal for raising this worry. 
11 This question is particularly relevant, as it has been argued that people who do not grasp the evaluative component of thick concepts lack conceptual competence (Väyrynen, 2011). The same, it seems, cannot be said about dual character concepts. Thus, it might be possible that conceptually competent people entertain concepts like artist and scientist without encoding any normative component.

12 See also Hampton (2006) who calls such structures "theory-based prototypes."

\section{ORCID}

Kevin Reuter (D) http://orcid.org/0000-0003-2404-1619

\section{WORKS CITED}

Alicke, M. (2008). Blaming badly. Journal of Cognition and Culture, 8(1), 179-186.

Aristotle (350 BCE/1976). Ethics. Translated by J. Thomson. London: Penguin Books.

Bielby, W. (2000). Minimizing workplace gender and racial bias. Contemporary Sociology, 29(1), 120-129.

Bielby, W., \& Baron, J. (1986). Men and women at work: Sex segregation and statistical discrimination. American Journal of Sociology, 91, 759-799.

Bird, A., \& Tobin, E. "Natural Kinds", The Stanford Encyclopedia of Philosophy (Spring 2018 Edition), Edward N. Zalta (ed.), https://plato.stanford.edu/archives/spr2018/entries/natural-kinds/

Blackburn, S. (1992). Through thick and thin. Proceedings of the Aristotelian Society, Supplementary Volume, 66, 284-299.

Bloom, P. (2007). Water as an artifact kind. In E. Margolis, \& S. Laurence (Eds.), Creations of the mind: Theories of artifacts and their representation.

Buckwalter, W., Rose, D., \& Turri, J. (2015). Belief through thick and thin. Noûs, 49(4), 748-775.

Chituc, V. (2012). Emotions as dual character concepts. Yale University: Unpublished Manuscript.

Del Pinal, G., Madva, A., \& Reuter, K. (2017). Stereotypes, conceptual centrality and gender bias: An empirical investigation. Ratio, 30(4), 384-410.

Del Pinal, G., \& Reuter, K. (2015). "Jack is a true scientist": On the content of dual character concepts. In Proceedings of the Cognitive Science Society. Pasadena, Ca: Cognitive Science Society.

Del Pinal, G., \& Reuter, K. (2017). Dual character concepts in social cognition: Commitments and the normative dimension of conceptual representation. Cognitive Science, 41, 477-501.

Elstein, D., \& Hurka, T. (2009). From thick to thin: Two moral reduction plans. Canadian Journal of Philosophy, 39, 515-536.

Gelman, S., \& Kremer, K. (1991). Understanding natural cause: Children's explanations of how objects and their properties originate. Child Development, 62(2), 396-414.

Hampton, J. (2006). Concepts as prototypes. The Psychology of Learning and Motivation: Advances in Research and Theory, 46 , 79-113.

Hare, R. (1981). Moral thinking. Oxford: Clarendon Press.

Haslanger, S. (2014). The normal, the natural and the good: Generics and ideology. Politica \& Società, 3(3), 365-392.

Kirchin, S. (2010). The shapelessness hypothesis. Philosophers' Imprint, 10(4), 1-28.

Knobe, J. (2003). Intentional action and side effects in ordinary language. Analysis, 63(279), 190-194.

Knobe, J., \& Fraser, B. (2008). Causal judgment and moral judgment: Two experiments. Moral Psychology, 2, 441-448.

Knobe, J., Prasada, S., \& Newman, G. (2013). Dual character concepts and the normative dimension of conceptual representation. Cognition, 127, 242-257.

Lakoff, G. (1975). Hedges: A study in meaning criteria and the logic of fuzzy concepts. In Contemporary research in philosophical logic and linguistic semantics (pp. 221-271). Dordrecht: Springer.

Leslie, S. J. (2008). Generics: Cognition and acquisition. Philosophical Review, 117(1), 1-47.

Leslie, S.-J. (2015). "Hillary Clinton is the only man in the Obama administration": Dual character concepts, generics, and gender. Analytic Philosophy, 56(2), 111-141.

Liao, S., Meskin, A., \& Knobe, J. (n.d.) (manuscript). Dual character art concepts. Unpublished manuscript, University of Leeds and Yale University.

Machery, E. (2005). Concepts are not a natural kind. Philosophy of Science, 72(3), 444-467.

Machery, E. (2014). Concepts: Investigating the heterogeneity hypothesis. In J. Sytsma (Ed.), Advances in experimental philosophy of mind. London, UK: Bloomsbury Publishing. 
Machery, E., \& Seppälä, S. (2011). Against hybrid theories of concepts. Anthropology and Philosophy, 10, 99-126.

Malt, B., \& Paquet, M. (2013). The real deal: What judgments of really reveal about how people think about artifacts. Memory \& Cognition, 41(3), 354-364.

Newman, G., Bloom, P., \& Knobe, J. (2014). Value judgments and the true self. Personality and Social Psychology Bulletin, 40(2), 203-216.

Newman, G., \& Knobe, J. (forthcoming). The essence of essentialism. Mind \& Language.

Newman, G. E., De Freitas, J., \& Knobe, J. (2015). Beliefs about the true self explain asymmetries based on moral judgment. Cognitive Science, 39(1), 96-125.

Phillips, J., De Freitas, J., Mott, C., Gruber, J., \& Knobe, J. (2017). True happiness: The role of morality in the folk concept of happiness. Journal of Experimental Psychology: General, 146, 1-76.

Putnam, H. (1973). Meaning and reference. Journal of Philosophy, 70(19), 699-711.

Putnam, H. (1975). The meaning of meaning. Minnesota Studies in the Philosophy of Science: Language, Mind, and Knowledge, 7, 131-193.

Putnam, H. (2002). The collapse of the fact/value dichotomy and other essays. Cambridge, MA: Harvard University Press.

Rangel, U., \& Keller, J. (2011). Essentialism goes social: Belief in social determinism as a component of psychological essentialism. Journal of Personality and Social Psychology, 100(6), 1056-1078.

Reuter, K., \& Del Pinal, G. (n.d.) (manuscript). Concepts in social cognition: Gender and the normative dimension of conceptual representation

Sloman, S., Love, B., \& Ahn, W. (1998). Feature centrality and conceptual coherence. Cognitive Science, 22(2), 189-228.

Tiberius, V. (2013). Theorizing: On the division of labor between moral philosophy and positive psychology. In S. Kirchin (Ed.), Thick concepts (pp. 217-234). Oxford: Oxford University Press.

Tobia, K., Newman, G., Knobe, J. (n.d.) (manuscript). Water is and is not $\mathrm{H}_{2} \mathrm{O}$. Available at SSRN: https://ssrn.com/abstract= 2933100 or doi: https://doi.org/10.2139/ssrn.2933100

Väyrynen, P. (2011). Thick concepts and variability. Philosophers' Imprint, 11, 1-17.

Väyrynen, P. (2013). The lewd, the rude and the nasty. New York: Oxford University Press.

Väyrynen, P. (2016). Thick ethical concepts. In E. N. Zalta (Ed.), The Stanford encyclopedia of philosophy (Fall 2017 ed.). https://plato.stanford.edu/archives/fall2017/entries/thick-ethical-concepts/

Vicente, A., \& Martínez-Manrique, F. (2014). The big concepts paper: A defence of hybridism. The British Journal for the Philosophy of Science, 67(1), 59-88.

Wedgwood, R. (forthcoming). The unity of normativity. In D. Star (Ed.), The Oxford handbook of reasons and normativity. Oxford University Press.

Weiskopf, D. (2009). The plurality of concepts. Synthese, 169(1), 145-173.

Williams, B. (1985). Ethics and the limits of philosophy. Cambridge, MA: Harvard University Press.

Wodak, D., Leslie, S. J., \& Rhodes, M. (2015). What a loaded generalization: Generics and social cognition. Philosophy Compass, 10(9), 625-635.

\section{AUTHOR BIOGRAPHY}

Kevin Reuter is a lecturer and post-doctoral researcher at the Institute of Philosophy, University of Bern. His research interests are in philosophy of mind and psychology, cognitive and social sciences, and experimental philosophy. He is also the principal investigator of the research project "The Conceptual Space of the Affective Mind" funded by the Swiss National Science Foundation.

How to cite this article: Reuter K. Dual character concepts. Philosophy Compass. 2019;14:e12557. https:// doi.org/10.1111/phc3.12557 